\title{
Correction to: Phosphaturic Mesenchymal Tumor in the Maxillofacial Region: A Diagnostic Dilemma
}

\author{
Adhithi Bhat ${ }^{1} \cdot$ Venkatesh Anehosur $^{2}$ (1) Niranjan Kumar ${ }^{3} \cdot$ Vinay M. Dipali $^{4}$. \\ Kiran Kumar ${ }^{5}$
}

Accepted: 20 April 2021/Published online: 10 May 2021

(C) The Association of Oral and Maxillofacial Surgeons of India 2021

\section{Correction to: J. Maxillofac. Oral Surg}

https://doi.org/10.1007/s12663-020-01496-8

The original version of this article unfortunately contained a mistake.

In page 2 , beginning of case report, currently reads: "in total, 32 year male patient" was incorrect.
The correct information is given below.

"32-year male patient".

The original article has been corrected.

Publisher's Note Springer Nature remains neutral with regard to jurisdictional claims in published maps and institutional affiliations.

The original article can be found online at https:// doi.org/10.1007/s12663-020-01496-8.

Venkatesh Anehosur

venkyrao12@yahoo.co.in

Adhithi Bhat

dradithibhat@gmail.com

Niranjan Kumar

drniranjankumar@sdmmedicalcollege.org

Kiran Kumar

drkirankumarop@gmail.com

1 HBTH Trauma Care Centre, Jogeshwari(E), Mumbai, India

2 Department of Oral and Maxillofacial Surgery, Craniofacial Surgery and Research Centre, SDM College of Dental Sciences and Hospital, Dharwad, Karnataka 580009, India

3 SDM College of Medical Sciences and Hospital, Sattur, Dharwad, Karnataka 580009, India

4 Consultant Endocrinologist and Diabetologist, SDM College of Medical Sciences and Hospital, Sattur, Dharwad,

Karnataka 580009, India

5 Department of Oral Pathology, SDM College of Dental Sciences and Hospital, Dharwad, Karnataka 580009, India 